\title{
Resveratrol prevents inflammation-dependent hepatic melanoma metastasis by inhibiting the secretion and effects of interleukin-18
}

\author{
Clarisa Salado ${ }^{1}$, Elvira Olaso ${ }^{2}$, Natalia Gallot ${ }^{3}$, Maria Valcarcel ${ }^{3}$, Eider Egilegor ${ }^{3}$, Lorea Mendoza ${ }^{3}$ and \\ Fernando Vidal-Vanaclocha ${ }^{4 *}$
}

\begin{abstract}
Background: Implantation and growth of metastatic cancer cells at distant organs is promoted by inflammationdependent mechanisms. A hepatic melanoma metastasis model where a majority of metastases are generated via interleukin-18-dependent mechanisms was used to test whether anti-inflammatory properties of resveratrol can interfere with mechanisms of metastasis.

Methods: Two experimental treatment schedules were used: 1) Mice received one daily oral dose of $1 \mathrm{mg} / \mathrm{kg}$ resveratrol after cancer cell injection and the metastasis number and volume were determined on day 12. 2) Mice received one daily oral dose of $1 \mathrm{mg} / \mathrm{kg}$ resveratrol along the 5 days prior to the injection of cancer cells and both interleukin-18 (IL-18) concentration in the hepatic blood and microvascular retention of luciferase-transfected B16M cells were determined on the $18^{\text {th }}$ hour. In vitro, primary cultured hepatic sinusoidal endothelial cells were treated with B16M-conditioned medium to mimic their in vivo activation by tumor-derived factors and the effect of resveratrol on IL-18 secretion, on vascular cell adhesion molecule-1 (VCAM-1) expression and on tumor cell adhesion were studied. The effect of resveratrol on melanoma cell activation by IL-18 was also studied.
\end{abstract}

Results: Resveratrol remarkably inhibited hepatic retention and metastatic growth of melanoma cells by $50 \%$ and 75\%, respectively. The mechanism involved IL-18 blockade at three levels: First, resveratrol prevented IL-18 augmentation in the blood of melanoma cell-infiltrated livers. Second, resveratrol inhibited IL-18-dependent expression of VCAM-1 by tumor-activated hepatic sinusoidal endothelium, preventing melanoma cell adhesion to the microvasculature. Third, resveratrol inhibited adhesion- and proliferation-stimulating effects of IL-18 on metastatic melanoma cells through hydrogen peroxide-dependent nuclear factor-kappaB translocation blockade on these cells.

Conclusions: These results demonstrate multiple sites for therapeutic intervention using resveratrol within the prometastatic microenvironment generated by tumor-induced hepatic IL-18, and suggest a remarkable effect of resveratrol in the prevention of inflammation-dependent melanoma metastasis in the liver.

\section{Background}

Individuals at high risk of metastasis from malignant tumors are a large group of patients that still does not receive an efficient treatment. The development of lowtoxicity drugs that target molecular mechanisms promoting intravascular dissemination, microvascular arrest,

\footnotetext{
* Correspondence: fernando.vidalvanaclocha@ceu.es

${ }^{4}$ CEU-San Pablo University School of Medicine, Institute of Applied Molecular Medicine (IMMA), Boadilla del Monte, Madrid, Spain

Full list of author information is available at the end of the article
}

and micrometastatic growth of cancer cells is becoming a feasible strategy to prevent adverse clinical effects of the metastatic disease in cancer patients. Because inflammation and oxidative stress have prometastatic implications at these subclinical stages of metastasis inception [1,2], agents that target specific genes and molecules that regulate these host responses to tumorderived factors may become good anti-metastatic candidates for clinical translation.

\section{C) Biomed Central}

(c) 2011 Salado et al; licensee BioMed Central Ltd. This is an Open Access article distributed under the terms of the Creative Commons Attribution License (http://creativecommons.org/licenses/by/2.0), which permits unrestricted use, distribution, and reproduction in any medium, provided the original work is properly cited. 
Resveratrol (RVL) -a phytopolyphenol that occurs in grapes and various other fruits and medicinal plants [3] - is a broad-spectrum anti-oxidant that inhibits the experimental development of several cancer types at diverse stages, metastasis included [4-5, for review see 6], and at relatively non-toxic doses. Not surprisingly, the effects exerted by RVL are consistent with its capacity to interact with molecular targets that are relevant during carcinogenesis, but also during metastasis. Specifically, RVL inhibits STAT3 and NF-kappaB-dependent transcription [6,7], Bcl-xL expression [8] and hypoxiainduced HIF-1alpha and VEGF [9], while it activates p53 [10] and TRAIL expression [11]. Moreover, nitric oxide initiates the progression of human melanoma via a feedback loop involving the apurinic/apyrimidinic endonuclease-1/redox factor-1, which is also inhibited by RVL [12]. However, much work needs to be done for a more complete understanding of its mechanisms of action and therefore, for a better assessment of its antitumor efficacy.

The experimental hepatic colonization of B16 melanoma (B16M) is a unique model for determining therapeutic intervention sites of natural antioxidant products, such as RVL, in the prometastatic microenvironment created in the liver by tumor-induced microvascular inflammation. Intrasplenic and left-cardiac ventricle $\mathrm{B} 16 \mathrm{M}$ cell injection routes are followed by formation of hepatic metastases, the majority of which are proinflammatory-cytokine dependent, as shown in IL-1beta- and IL-1 converting enzyme-deficient mice [13], and with recombinant IL-1 receptor antagonist [14] and IL-18 binding protein treatments [15]. Consistent with melanoma metastasis regulation by proinflammatory cytokines, response of primary cultured hepatic sinusoidal endothelium (HSE) to B16M cell soluble factors remarkably increased cancer cell adherence to tumor-activated endothelium. This is due to a sequential process involving TNF-alpha-dependent IL-1beta, which in turn induced IL-18 to upregulate VCAM-1 via hydrogen peroxide $\left(\mathrm{H}_{2} \mathrm{O}_{2}\right)$ [16]. Moreover, blockade of VCAM-1 with specific antibodies prior to $\mathrm{B} 16 \mathrm{M}$ cell injection significantly decreased hepatic retention of B16M cells and metastasis development [17]. Because VCAM-1 expression is oxidative stress-inducible, in vivo administration of recombinant catalase resulted in a complete abrogation of both enhanced VCAM-1 expression by HSE cells obtained from tumor-injected mice and increased B16M cell adhesion to those HSE [16]. The pivotal position of $\mathrm{H}_{2} \mathrm{O}_{2}$ in this metastasis model was further supported by the fact that incubation of HSE cells with non-toxic concentrations of $\mathrm{H}_{2} \mathrm{O}_{2}$ also directly enhanced in vitro VCAM-1-dependent B16M cell adhesion without inflammatory cytokine mediation [16]. B16M cells also responded to hepatic-derived IL-18 by enhanced proliferation [15] and increased adhesion to HSE via a VLA-4-dependent mechanism [17].

In this study, we investigated the effect of RVL on the microvascular phase of the hepatic metastasis process of B16M cells. First, the effects of RVL on the capillary arrest and early metastatic growth of intrasplenicallyinjected B16M cells were studied in vivo. Second, because IL-18 regulates melanoma metastasis occurrence via VLA-4-dependent B16M cell adhesion to HSE, the effects of RVL on IL-18 secretion and VCAM-1 expression by hepatic sinusoidal cells, and on the cancer cell response to IL-18 were studied in vitro.

Our results showed that RVL remarkably inhibited both hepatic microvascular retention and metastatic development of B16M cells. In vitro, RVL completely abrogated the melanoma cell adhesion to tumor-activated HSE operated via VLA-4/VCAM-1 interaction. Our results also showed that the antimetastatic effect of RVL was exerted in this model through an efficient blockade of IL-18 effects, which was secreted by tumoractivated hepatic tissue and promoted VLA-4-dependent melanoma cell adhesion and proliferation via hydrogen peroxide-dependent NFkappaB activation. These findings suggest that RVL can act as a powerful inhibitor in the prometastatic microenvironment of hepatic inflammation generated by tumor-induced host IL-18.

\section{Materials and methods}

\section{Cells and culture conditions}

B16M cells (B16F10 subline) were cultured in DMEM supplemented with $10 \%$ FCS and penicillin-streptomycin (Sigma Chemicals Co., St. Louis, MO) [10]. B16M-conditioned medium (B16M-CM) was obtained from subconfluent cells cultured for 12 hours as previously described [13].

\section{Hepatic metastasis model and treatment schedule}

Syngeneic C57BL/6J mice (male, 6-8 weeks old) were obtained from IFFA Credo (L'Arbreole, France). Animal housing, care, and experimental conditions were conducted in conformity with institutional guidelines, in compliance with the relevant national and international laws and policies. Hepatic metastases were produced by intrasplenic injection of B16 cells as previously described [14]. Mice were killed on the twelfth day afterwards. Liver tissue was processed for histology [14]. Fifteen 4 $\mu \mathrm{m}$-thick tissue sections of formaldehyde-fixed liver (five groups, separated $500 \mu \mathrm{m}$ ) were stained with H\&E. An integrated image analysis system (Olympus Microimage 4.0 capture kit) connected to an Olympus BX51TF microscope was used to quantify the number, average diameter, and position coordinates of metastases. Percentage of liver volume occupied by metastases and metastasis density (foci number $/ 100 \mathrm{~mm}^{3}$ ) were also 
determined [14]. In order to study the effect of RVL (Sigma-Aldrich Chemicals Co, St Louis, MO) on hepatic metastasis development, some mice (10 per group) received $1 \mathrm{mg} / \mathrm{kg} /$ day $\mathrm{RVL}$ dissolved in ethanol (5\%), via intragastric tube, from day 1 to 12 . Control mice received the same volume of vehicle. Each experiment was carried out three times.

\section{Quantitative assay on hepatic retention of circulating melanoma cells}

B16M cells were stably transfected with a construct containing the Photinus pyralis luciferase gene coding sequence under transcriptional control of the cytomegalovirus promoter and the neomycin resistance gene [16]. Three hundred thousand viable luciferase-transfected B16M cells were intrasplenically injected into C57BL/6 mice $(n=30)$. Some mice received $1 \mathrm{mg} / \mathrm{kg} /$ day $\mathrm{RVL}$ five days prior to B16M-Luc cell injection. All mice were killed 18 hours later, and livers were analyzed for luciferase activity (Promega Co., Madison, WI) as described previously [16].

Isolation of hepatic sinusoidal cells and enriched primary culture of endothelial cells

HSE cells were isolated from syngeneic C57BL/6J mice (male, 6-8 weeks old) identified, and cultured as described previously [16]. Briefly, isolated mouse liver cells were obtained by two-step collagenase perfusion. A non-parenchymal liver cell fraction was further purified by centrifugation in a Percoll ${ }^{\circledR}$ gradient (Amersham; Uppsala, Sweden). Kupffer cells were then removed by selective adherence to plastic substrate, HSE cells were phenotypically characterized by flow cytometry analysis with specific antibodies against CD31 (PECAM-1 Sigma, St Louis), HLA class II and CD40, (both from BD Biosciences); CD106 (VCAM-1) and CD14 (both fromBD Pharmingen, San Diego, CA), smooth muscle alpha actin (ASMA, Sigma-Aldrich, St Louis, MO). HSE cells were seeded at $2 \times 10^{5}$ cells/well in RPMI-1640 culture medium (Sigma Chemicals, St. Louis, MO) supplemented with $10 \%$ FCS (Life Technologies, Gaithersburg, $\mathrm{MD}$ ) onto 24-well tissue culture plates pre-coated with type I collagen solution $(0.03 \mathrm{mg} / \mathrm{ml})$ (Collagen Biomaterials, Palo Alto, CA) and allowed to spread for $45 \mathrm{~min}$ at $37^{\circ} \mathrm{C}$ and $5 \% \mathrm{CO}_{2}$.

\section{Enzyme immunoassay of IL-18 concentration in hepatic blood and supernatants of cultured cells}

Serum samples were obtained from hepatic (suprahepatic vein) blood of adult male C57/B1/6J mice 18 hours after intrasplenic injection of B16M cells. Some mice received ( $1 \mathrm{mg} / \mathrm{kg} /$ day) RVL from day 1 to 5 via intragastric tube prior to melanoma cells injection. Primary cultured HSE cells were incubated in the presence of absence of 2.5 $\mu \mathrm{M}$ RVL or recombinant VEGF antibody for $30 \mathrm{~min}$, after which B16M-CM or $10 \mathrm{ng} / \mathrm{ml}$ of recombinant VEGF were added. Eight hours later, the supernatant from the treated HSE cells were collected. IL-18 concentration in serum from hepatic blood or in culture cell media was detected using a competitive enzyme immunoassay (R\&D Systems, Minneapolis, MN).

\section{Immunohistochemical analysis of p65 nuclear translocation}

B16M cells $\left(1 \times 10^{4}\right.$ cells/well $)$ were grown on $8 \mu \mathrm{m}$ chamber glass slides. Cells were serum-starved for 24 $\mathrm{h}$ and treated with $\mathrm{IL}-18(100 \mathrm{ng} / \mathrm{ml})$ for 30,60 and $120 \mathrm{~min}$. In some experiments, cells received $2.5 \mu \mathrm{M}$ RVL 30 min prior to IL-18 treatment. Once treatment time had finished, cells were fixed in $4 \%$ formaldehyde (in PBS) for $30 \mathrm{~min}$ at room temperature and permeabilized in $1 \%$ SDS for $10 \mathrm{~min}$. Non-specific binding was blocked for 1 hour with 10\% bovine serum in PBS buffer. Cells were incubated with $1.5 \mu \mathrm{g} / \mathrm{ml}$ rabbit antip65 polyclonal antibody (Santa Cruz Biotechnology Inc., Santa Cruz, CA) for $1 \mathrm{~h}$ at room temperature. Further wash steps removed unbound antibody prior to the addition of the secondary Alexa 594 goat antirabbit antibody. Images were acquired on a BD Pathway $^{\mathrm{TM}}$ Bioimager.

\section{Western blot analysis of p65 in nuclear fractions}

Subconfluent cultures of B16M cells were treated as above described for $60 \mathrm{~min}$. Then, they were harvested and incubated in lysis buffer (10 mM HEPES ( $\mathrm{pH} 7.9)$, $10 \mathrm{mM} \mathrm{KCl}, 0.1 \mathrm{mM}$ EDTA, $0.1 \mathrm{mM}$ DTT, 0.1\% Nonidet P-40 and $0.5 \mathrm{mM}$ PMSF) for 20 minutes on ice. The crude nuclei were collected by centrifugation, further incubated in $20 \mathrm{mM}$ HEPES ( $\mathrm{pH} 7,9), 0.4 \mathrm{mM} \mathrm{NaCl}, 1$ mM EDTA, 1 mM DTT, $1 \mathrm{mM}$ phenylmethylsulfonyl fluoride (PMSF) for 20 minutes on ice and clarified by micro-centrifugation and frozen. Fifty micrograms of nuclear extracts were resolved on $12 \%$ of SDS-PAGE and p65 protein was analyzed by Western blot using rabbit polyclonal antibody (Santa Cruz Biotechnology, Santa Cruz, CA). Lamin-B expression was used as loading control.

\section{Western Blot analysis of VCAM-1}

Freshly isolated HSE cells were seeded onto 24-well plates for 24 hours. Then, they were cultured for 12 hours in the presence of basal medium, B16M-CM or 1 $\mathrm{ng} / \mathrm{ml}$ IL-18. In some experiments, HSE cells received $2.5 \mu \mathrm{M}$ RVL 30 min prior to B16M-CM or IL-18 treatment. HSE cells were disrupted in $50 \mathrm{mM}$ Tris (pH 7.5), $150 \mathrm{mM} \mathrm{NaCl}, 1 \% \mathrm{NP} 40,0.5 \%$ deoxycholic acid, $0.1 \%$ SDS, 2 mM EDTA, $10 \mathrm{mM}$ NaF, $10 \mu \mathrm{g} / \mathrm{ml}$ leupeptin, 20 $\mu \mathrm{g} / \mathrm{ml}$ aprotinin, and $1 \mathrm{mM}$ PMSF. Then, $40 \mu \mathrm{g}$ of 
protein from cell lysates were separated by $12 \%$ SDSPAGE followed by Western analysis using rat antimouse VCAM-1 monoclonal antibody and $\beta$-tubulin (both from Santa Cruz Biotechnology, Santa Cruz, CA) and the appropriate secondary antibodies.

Blot was imaged using a Syngene G-Box gel imaging system (Synoptics Ltd., Cambridge) and band density analyzed using Gene Tools analysis software.

Measurement of $\mathrm{H}_{2} \mathrm{O}_{2}$ production from B16M cells in vitro $\mathrm{B} 16 \mathrm{M}$ cells were cultured in DMEM without phenol red with $20 \mu \mathrm{mol} / \mathrm{L}$ 2', 7'-dichlorofluorescein-diacetate (DCFH-DA) as described [12]. $\mathrm{H}_{2} \mathrm{O}_{2}$ produced by incubated cells oxidizes DCFH to the highly fluorescent DCF so that fluorescence intensity is directly proportional to the amount of $\mathrm{H}_{2} \mathrm{O}_{2}$ produced by the cells. DCF fluorescence was recorded at 485/22-nm excitation and 530/25-nm emission filters. Non-DCFH-DA-incubated cells were used to determine basal autofluores-

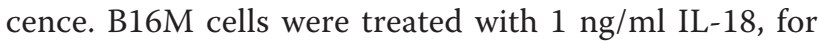
2 hours. In some experiments B16M cells were incubated with $2.5 \mu \mathrm{M}$ of RVL 30 minutes prior to IL-18 addition. $\mathrm{H}_{2} \mathrm{O}_{2}$ production per well was quantified in arbitrary fluorescence units after subtracting basal autofluorescence.

\section{Proliferation assay}

B16M cells were cultured overnight in DMEM plus 10\% FCS. Then, they were incubated for 72 hours in the presence of $0.1 \mathrm{ng} / \mathrm{ml} \mathrm{IL-18}$ supplemented with $0.5 \%$ FCS. Control cells received the same culture medium without the cytokine. In some experiments, $2.5 \mu \mathrm{M}$ RVL was added to control and IL-18-treated B16M cells. After 48 hours incubation, B16M cell proliferation was measured using sulforhodamine 101 protein assay, as described previously [15].

\section{B16M cell adhesion assay to primary cultured hepatic endothelial cells}

B16M cells were labeled with 2', 7'-bis-(2-carboxyethyl)5,6-carboxyfluoresceinacetoxymethylester solution (Molecular Probes, Eugene, OR) and added to primary culture of HSE cells $\left(2 \times 10^{5}\right.$ cells/well). Eight minutes later, wells were washed three times with fresh medium. The number of adhering cells was determined using a quantitative method based on a previously described fluorescence measurement system [14]. HSE were treated with B16M-CM for 6 hours prior to the addition of B16M cells. In some experiments, HSE cells received 2.5 $\mu \mathrm{M}$ RVL or vehicle 30 minutes prior to B16M-CM. In other experiments, B16M cells were pretreated with IL18 for 6 hours prior to the adhesion assay. In this case, $\mathrm{B} 16 \mathrm{M}$ cells received $2.5 \mu \mathrm{M}$ RVL or vehicle 30 minutes before IL-18.

\section{Statistical analyses}

Data were expressed as means \pm SD. Statistical analysis was performed by SPPS statistical software for Microsoft Windows, release 6.0 (Professional Statistic, Chicago, IL). Homogeneity of the variance was tested using the Levene test. If the variances were homogeneous, data were analyzed by using one-way ANOVA test with Bonferroni's correction for multiple comparisons when more than two groups were analyzed. For data sets with non-homogeneous variances, ANOVA test with Tamhane's posthoc analysis was applied. Individual comparisons were made with Student's two-tailed, unpaired $t$ test (program Statview 512; Abacus Concepts, Inc., for Macintosh). The criterion for significance was $\mathrm{P}<0.01$ for all comparisons.

\section{Results}

\section{Resveratrol inhibits hepatic seeding and growth of} metastatic melanoma cells

RVL given orally at $1 \mathrm{mg} / \mathrm{kg}$ from day 1 to 12 after B16M cell injection reduced hepatic metastasis volume by $75 \%$ as compared to control mice treated with vehicle (Figure 1A-1E). Antimetastatic activities of RVL did not involve any secondary effect that might compromise animal survival. The same treatment schedule also significantly $(\mathrm{P}<0.01)$ decreased metastasis number by $50 \%$ (Figure 1E). Moreover, majority of metastases developed in RVL-treated mice were on average significantly smaller (by 60\%) than those developed in vehicletreated mice. Therefore, B16M cells predominantly colonized hepatic tissue through RVL-sensitive mechanisms. Consistent with RVL-dependent decrease in hepatic metastasis number, oral administration of the same daily dose of RVL to animals during 5 days prior to cancer cell injection, led to a statistically significant $(\mathrm{P}<0.01)$ hepatic retention decrease by $45 \%$ of luciferase-transfected B16M cells (Figure 2.). Moreover, although antimetastatic effects of RVL affected 50\% of metastases, hepatic metastasis volume decreased by $75 \%$, indicating that either RVL-resistant metastasis had a slower growth rate than RVL-sensitive ones, or that metastasis implantation by RVL-resistant mechanism still had a RVL-sensitive growth mechanism.

Consistent with previous reports [18], our histologic study (Figure 1B and 1D) showed that hepatic melanoma metastases from vehicle-treated mice were predominantly of sinusoidal-type, containing a rich network of intratumoral microvessels supported by sinusoidalderived myofibroblasts; while a minority were of portaltype, containing a lower density of intratumoral microvessels, mainly supported by portal tract-derived myofibroblasts. Interestingly, RVL decreased by $80 \%$ sinusoidal-type metastasis number, while it did not alter the number of portal-type metastasis, indicating that 


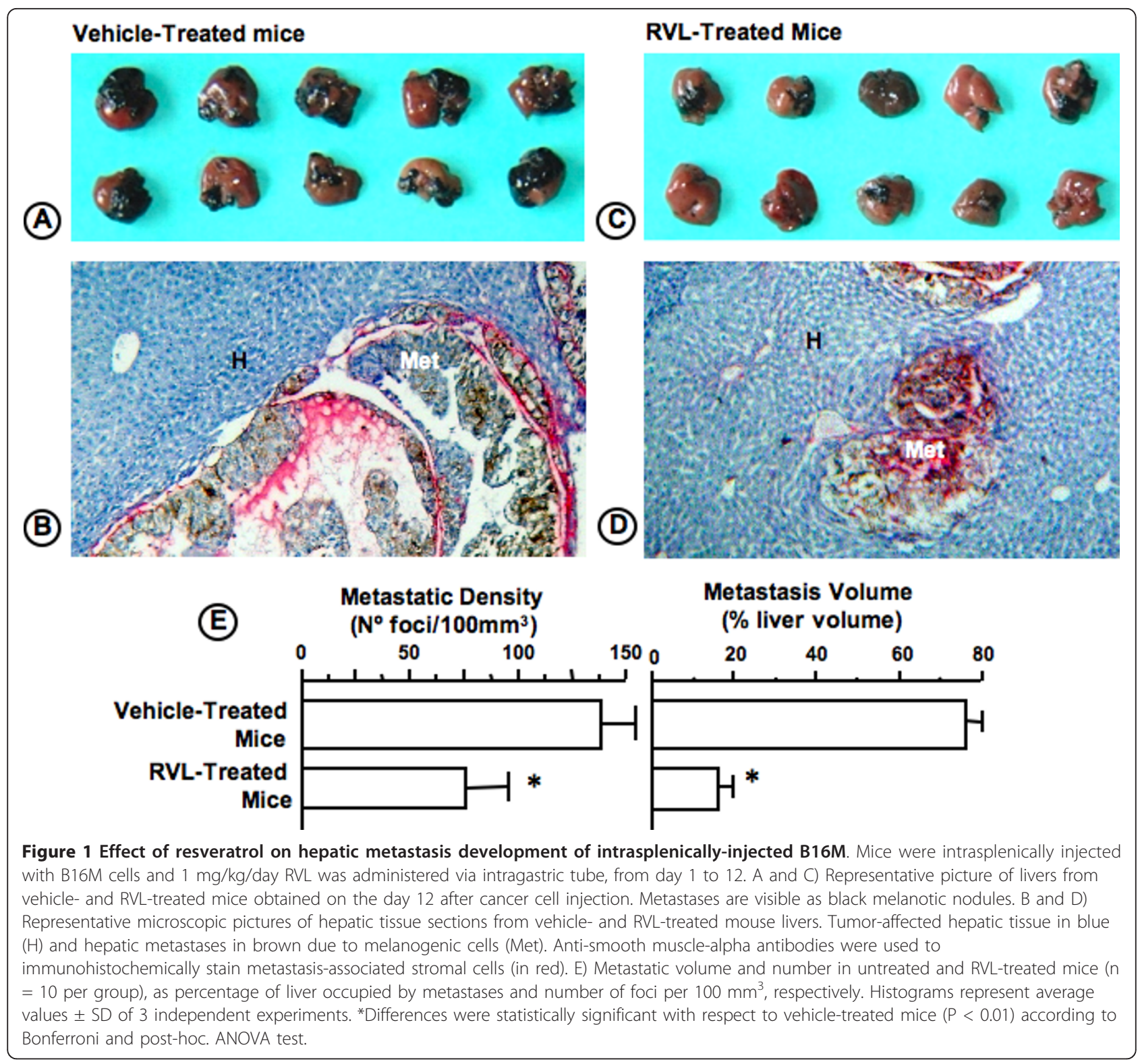

RVL-sensitive metastases were of sinusoidal-type (E Olaso, C Salado, B Arteta, A Lopategi, F Vidal-Vanaclocha: Resveratrol inhibits the proangiogenic response of hepatic sinusoidal cells to tumor-derived soluble factors during liver metastasis by colon carcinoma, submitted).

Resveratrol inhibits hepatic secretion of IL-18 induced by infiltrating metastatic melanoma cells

Previously, we reported that IL-18 increased in hepatic venous blood over basal level during the sinusoidal inflammation associated with liver-infiltrating cancer cells $[13,15]$. A similar 5 day-RVL pretreatment schedule as above also completely abrogated the augmentation of IL-18 concentration in the hepatic blood obtained 18 hours after B16M cell injection into treated mice, without affecting the physiological levels of this cytokine in mice not injected with tumor cells (Figure 3A). In order to discard that the increase in plasma IL-18 might reflect a decreased hepatic metabolism of this cytokine subsequent to the metastasis process [19], we next determined the effect of RVL on IL-18 secretion from tumor-activated hepatic sinusoidal cells. Primary cultured HSE cells received either RVL or vehicle $30 \mathrm{~min}$ prior to being treated with B16M-CM for 8 hours and the level of IL-18 was measured in the supernatant by ELISA. As shown in Figure 3B, RVL abolished the augmentation of IL-18 concentration in B16-CM-treated HSE cells, while it did not affect basal IL-18 concentrations in the supernatant of untreated primary cultured HSE cells. 


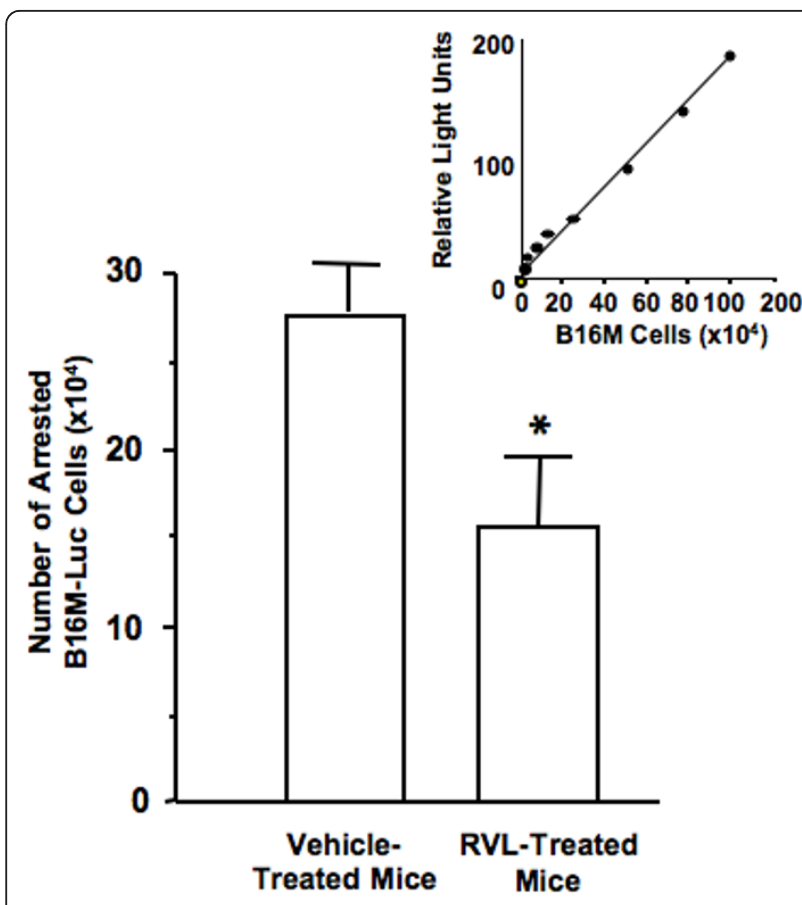

Figure 2 Effect of resveratrol on melanoma cell retention in the hepatic microvasculature of intrasplenically-injected B16M RVL was administrated via intragastric tube $(1 \mathrm{mg} / \mathrm{kg} /$ day $)$ during 5 days prior to $3 \times 10^{5}$ B16M-Luc cell intrasplenic injection. After 18 hours livers were removed and light production was measured as described in Methods. Light emission values were expressed as relative light units and the number of arrested B16M-Luc cells was calculated on the basis of a standard curve relating specific relative light units to B16M-Luc cell number. Data represent average values \pm SD of two separate experiments. *Differences were statistically significant $(P<0.01)$ to respect to vehicle-treated mice, by Student's two tailed, unpaired t test

Previously, we showed that the pro-adhesive effect of IL-18 on tumor-activated HSE cells was VEGF-dependent [20]. Herein, we showed that anti-murine VEGF antibody completely abrogated IL-18 secretion from tumor-activated HSE cells and that RVL abolished IL-18 production from VEGF-activated HSE cells. Therefore, RVL inhibited IL-18 secretion from tumor-activated HSE cells through the specific inhibition of tumorderived VEGF on HSE (Figure 3B).

\section{Resveratrol inhibits IL-18-induced VCAM-1 expression on} tumor-activated hepatic sinusoidal endothelium, preventing microvascular adhesion of melanoma cells Because IL-18 promotes the adhesion of B16 melanoma cells to the hepatic microvascular endothelium via VCAM-1-dependent mechanism $[13,15]$, we next studied the effect of RVL on the VCAM-1 expression level in primary cultured hepatic endothelial cells given either recombinant murine IL-18 or B16M-CM. As shown in Figure 4A, pretreatment of HSE cells with RVL

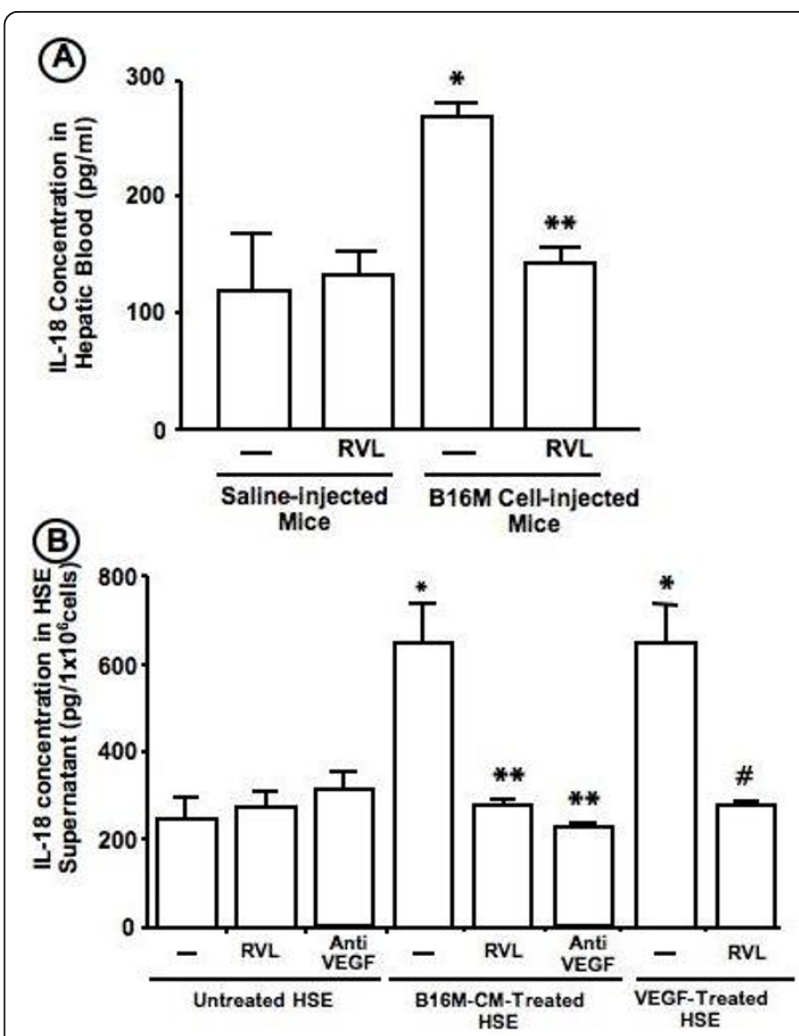

Figure 3 Effect of RVL on IL-18 secretion from tumor-activated HSE cells in vivo and in vitro. A) IL-18 levels were determined in serum samples obtained from suprahepatic vein blood on the $18^{\text {th }}$ hour after intrasplenic injection of $3 \times 10^{5} \mathrm{~B} 16 \mathrm{M}$ cells. Some mice received $1 \mathrm{mg} / \mathrm{kg} /$ day RVL via intragastic tube 5 days prior to cancer cells injection. B) Primary cultured HSE cells were incubated in the presence or absence of $2.5 \mu \mathrm{M}$ RVL or recombinant VEGF antibody for $30 \mathrm{~min}$, and then with either B16M-CM or $10 \mathrm{ng} / \mathrm{ml}$ recombinant murine VEGF. Eight hours later, the supernatants from treated HSE cells were collected and IL-18 concentration

determined by ELISA. Data represent the average values \pm SD of 3 independent experiments. *Differences were statistically significant $(P<0.01)$ to respect to vehicle-treated mice, by Student's two tailed, unpaired $t$ test.

abrogated VCAM-1 expression increase in HSE cells given either IL-18 or B16M-CM. Consistently, RVL also abolished the adhesion of B16M cells to HSE cells given the same B16M-CM for 6 hours prior to adhesion assays (Figure $4 \mathrm{~B}$ ).

\section{Resveratrol inhibits adhesion- and proliferation-} stimulating effects of IL-18 on metastatic melanoma cells As assessed by RT-PCR and flow cytometry, B16M cells expressed IL-18 receptor alpha under basal culture conditions $[15,17]$. Therefore, together with proinflammatory effects of IL-18 on HSE cells, melanoma cell function might also be affected by HSE-derived IL-18 in the microenvironment of tumor-activated liver [13]. As shown in Figure $5 \mathrm{~A}$, in vitro treatment with RVL 


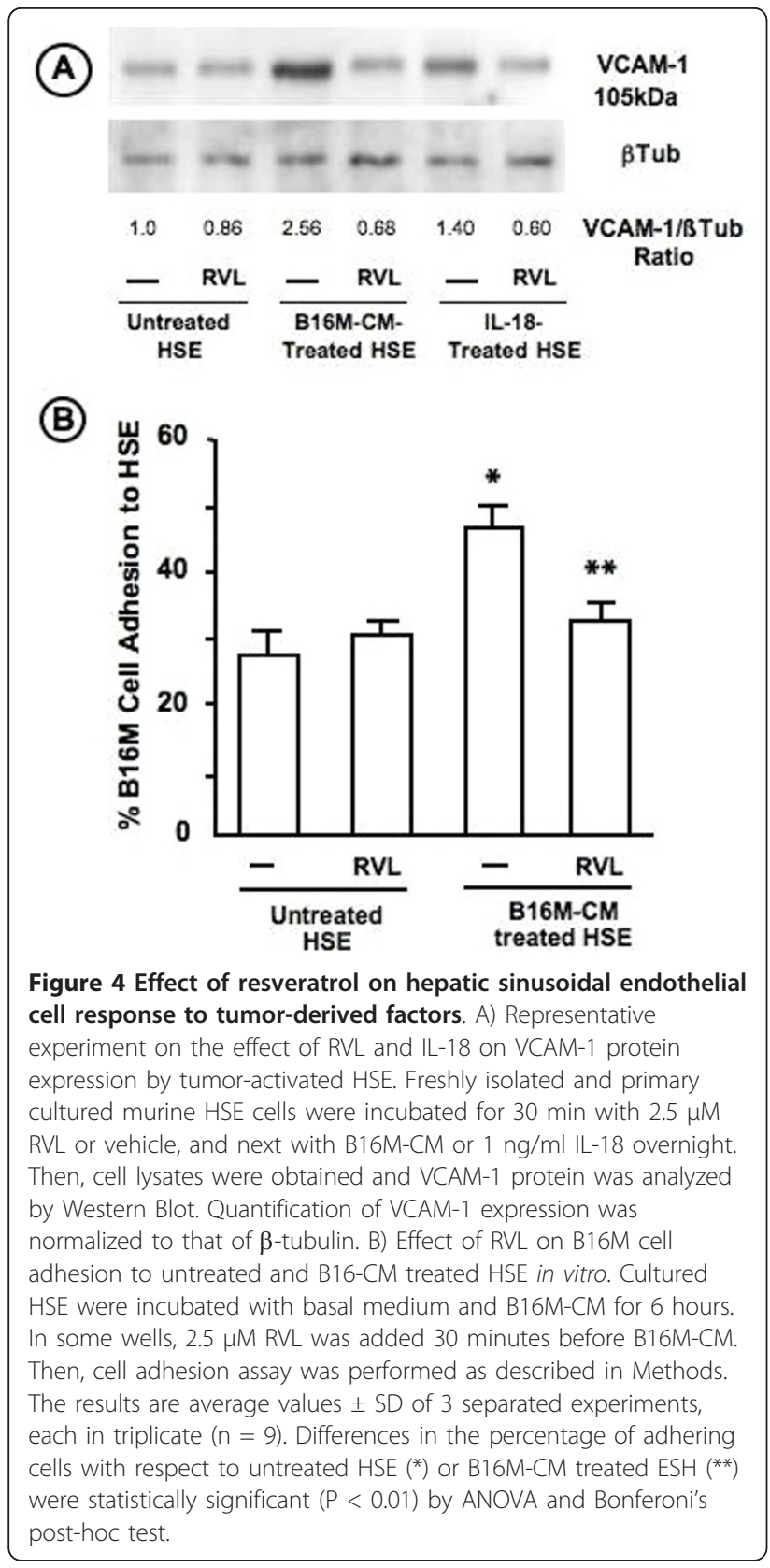

completely abrogated the hepatic microvascular arrest augmentation induced in B16M cells given $1 \mathrm{ng} / \mathrm{ml} \mathrm{IL-}$ 18 for 6 hours prior to their intrasplenic injection into normal mice. The same treatment schedule with RVL also prevented both $\mathrm{B} 16 \mathrm{M}$ cell adhesion to primary cultured HSE cells and B16M cell proliferation induced in IL-18-pretreated B16M cells, without affecting these functional activities in basal condition-cultured $\mathrm{B} 16 \mathrm{M}$ cells (Figure $5 \mathrm{~B}$ and $5 \mathrm{C}$ ). Because IL- 18 regulates $\mathrm{H}_{2} \mathrm{O}_{2}$ production from B16M-CM-treated HSE cells [16], we next studied the effect of RVL on $\mathrm{H}_{2} \mathrm{O}_{2}$ production from IL-18-treated B16M cells. Interestingly, B16M cells given $1 \mathrm{ng} / \mathrm{ml} \mathrm{IL-18}$ for 2 hours significantly $(\mathrm{P}<0,01)$ increased their $\mathrm{H}_{2} \mathrm{O}_{2}$ production. However, this cytokine-induced oxidative reaction was completely neutralized when B16M cells received RVL 30 min prior to IL18 (Figure 5D). Moreover, NF-kB activation is a known pathway for attenuating cancer cell response to inflammatory mediators. Therefore, we examined the nuclear translocation of $\mathrm{p} 65$, the transcriptionally active subunit of NF-kB, in cultured B16M cells given recombinant murine IL-18 (Figure 5E and 5F). First, as shown immunofluorescence using an anti-p65 antibody (Figure 5E), p65 remained cytosolic under basal conditions and no change was observed when basal condition-cultured cells received RVL. In contrast, a 60 min stimulation with IL-18 $(100 \mathrm{ng} / \mathrm{mL})$ remarkably induced p65 translocation into the nucleus. P65 translocation persisted for 120 min (data not shown). However, addition of RVL to IL-18-treated cells completely abrogated p65 translocation (Figure 5E). Second, similar results were obtained when nuclear extracts from same experimental conditions as above were analyzed for $\mathrm{p} 65$ protein expression by Western blot (Figure 5F). Our data therefore indicates that IL-18 activates NF-kB in B16M cells and that RVL can efficiently inhibits this activation.

\section{Discussion}

We demonstrated that resveratrol prevented inflammation-dependent hepatic melanoma metastasis by inhibiting both secretion of IL-18 from tumor-affected liver and effects of hepatic IL-18 on melanoma cells. Daily treatment with RVL significantly inhibited murine melanoma metastasis occurrence and development. Consistent with these effects, oral administration of RVL during 5 days prior to melanoma cell injection inhibited both IL-18 augmentation in the hepatic blood and melanoma cell retention in the hepatic microvasculature of melanoma cell-injected mice. This was further supported by in vitro experiments where RVL also inhibited IL-18 secretion, VCAM-1 expression and melanoma cell adhesion to tumor-activated HSE cells, three interrelated events regulating the microvascular arrest of circulating melanoma cells in the liver [2]. Our results also revealed that RVL blocked both in vitro VLA-4-dependent microvascular adhesion and proliferation in IL-18-treated melanoma cells, suggesting that RVL may also exert its antimetastatic effect by preventing melanoma cell response to endogenous hepatic IL-18. Not surprisingly, both adhesion and proliferation were upregulated in IL18-treated melanoma cells via hydrogen peroxide-dependent NF-kappaB activation, which was inhibited by RVL in this tumor model. Therefore, our findings provide evidence that RVL inhibited IL-18 secretion from tumor-activated hepatic tissue, and subsequently, IL-18 effects on both host and cancer cells, which prevented 


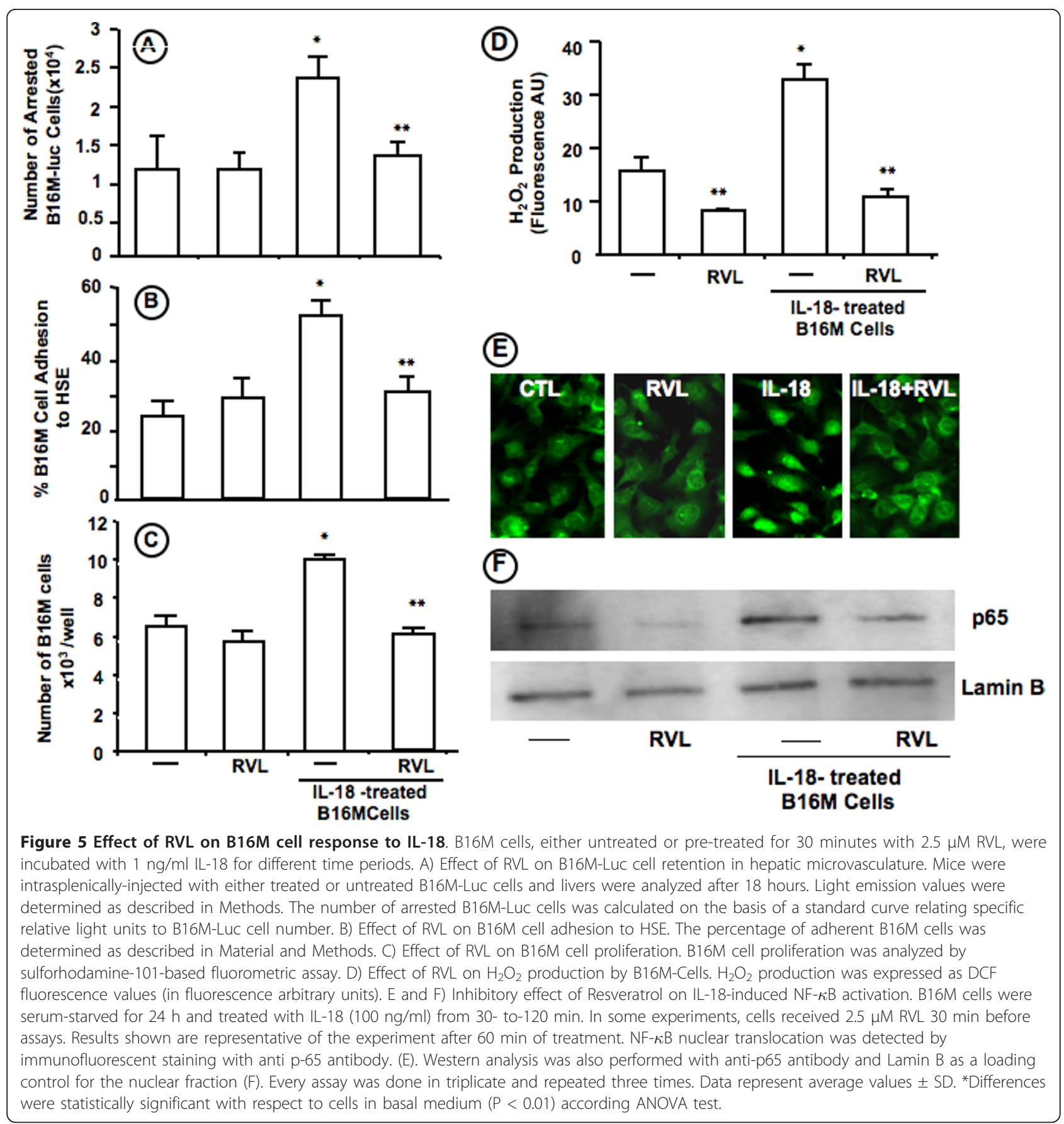

the inflammation-dependent metastasis class in the prometastatic microenvironment created by tumor-induced IL-18 in the liver.

Previous studies have already reported about antimetastatic effects of RVL on various rodent and human solid tumors [5,6,21-23]. However, specific therapeutic intervention sites of RVL along metastasis process are still unclear. Herein, a hepatic melanoma metastasis model-where majority of metastases are generated via
IL-18-dependent inflammatory mechanisms [13,15]-, served to demonstrate that RVL specifically interferes with inflammation-dependent metastases that develop in the liver through oxidative stress-mediated mechanisms. It has already been reported that RVL has beneficial effects in pathogenic conditions of the liver that involve an overproduction of inflammatory cytokines, such as cholestasis [24], alcohol injury [25], and LPS [26]. More importantly, it has also been shown that RVL suppresses 
oxidative stress and inflammatory response in diethylnitrosamine-initiated rat hepatocarcinogenesis $[5,6]$. However, at the moment RVL has not yet been reported as a potential inhibitor of prometastatic effects of hepatic inflammation created in the liver microenvironment by tumor-induced IL-18.

IL-18 is a proinflammatory cytokine that increases in the blood of the majority of cancer patients and that has been associated with disease progression and, in some cancer types, even with metastatic recurrence, poor clinical outcome and survival [17]. While recombinant IL18 has very limited therapeutic activity as a single agent in patients with metastatic melanoma [27], preclinical studies have shown that IL-18 binding protein inhibits hepatic and lung metastases in murine models $[15,28]$. This is further supported by studies revealing that IL18-dependent mechanisms promote immune escape [29], microvascular adherence [13], resistance to UVBinduced apoptosis [30], and angiogenesis [18,31]. Therefore, the fact that RVL completely abrogated the increase of hepatic blood IL-18 induced by tumorderived factors suggests the potential use of RVL as a hepatic metastasis chemopreventive agent in cancer patients at high risk of hepatic metastasis, such as those suffering from a malignant uveal melanoma.

IL-18 is also a major IFN-gamma-inducing factor and both IL-18 and IFN-gamma act together in the host response to infection, but also in the pathogenesis of acute hepatic injury [32]. In our model, abrogation of tumor-induced hepatic IL-18 did not involve any decrease of IFN-gamma level, which also significantly increased in the hepatic blood of same animals (data not shown). This suggests that IL-18-independent pathways were also operating in the induction of IFNgamma secretion during tumor metastasis development in this model.

Previously, we have reported that liver-infiltrating B16M cells activated their adhesion to HSE cells through a sequential process involving TNF-alphadependent IL-1beta, which in turn induced IL-18 to upregulate VCAM-1 via $\mathrm{H}_{2} \mathrm{O}_{2}[13,16]$. The pivotal position of IL-18-induced $\mathrm{H}_{2} \mathrm{O}_{2}$ was further supported by the fact that incubation of HSE cells with nontoxic concentrations of $\mathrm{H}_{2} \mathrm{O}_{2}$ directly enhanced VCAM-1-dependent $\mathrm{B} 16 \mathrm{M}$ cell adhesion in vitro without pro-inflammatory cytokine mediation, which emphasizes the key role of oxidative stress in the pathogenesis of IL-18-dependent hepatic metastasis [16]. Our current results show that RVL abolished $\mathrm{H}_{2} \mathrm{O}_{2}$ production from IL-18-treated melanoma cells. This has implications in several mechanisms: first, because it prevents oxidative stressdependent VLA-4 integrin activation in melanoma cells; second, because it prevents nuclear translocation of NFkappaB, which is oxidative stress-dependent as well; and third, because it blocks IL-18 receptor-expressing melanoma cell subpopulation enlargement [17].

RVL also decreased metastasis number by $50 \%$, suggesting that hepatic colonization of this murine melanoma occurred via RVL-sensitive and RVL-resistant mechanisms. However, hepatic metastasis volume decreased by $75 \%$, indicating that either RVL-resistant metastases had a slower growth rate than RVL-sensitive ones, or that most of metastasis implantation by RVLresistant mechanism still had a RVL-sensitive growth mechanism. According to our results, RVL-dependent metastatic growth inhibition it may depend in part on direct anti-proliferative effects of RVL on IL-18-dependent melanoma cells. It also may be due to a decrease of angiogenic parameters in hepatic B16M metastases from RVL-treated mice (E Olaso, C Salado, B Arteta, A Lopategi, F Vidal-Vanaclocha: Resveratrol inhibits the proangiogenic response of hepatic sinusoidal cells to tumor-derived soluble factors during liver metastasis by colon carcinoma, submitted). In this case, the mechanism appears to depend on the remarkable inhibitory effect of RVL on the proangiogenic effects of tumoractivated hepatic myofibroblasts [18].

In summary, this study uncovers multiple therapeutic intervention sites for RVL in the inflammatory microenvironment of tumor-activated hepatic sinusoids occurring prior to metastasis development (Figure 6). First, RVL inhibited hepatic secretion of IL-18 induced by liver-infiltrating melanoma cells; second, it prevented IL-18-dependent VCAM-1 expression on the hepatic microvasculature which decreased by $50 \%$ the microvascular retention of melanoma cells in the liver; and third, it prevented melanoma cell responses to hepatic IL-18, further affecting VLA-4-dependent melanoma cell adhesion and proliferation. Therefore, by acting on host and tumor-dependent responses to IL-18, RVL very efficiently inhibited cancer cell arrest and growth initiation in the tumor microenvironment. Thus, this study uncovers a pathophysiological mechanism accounting for the metastasis-chemoprevention effect of a natural product in the liver.

\section{Abbreviations \\ B16M: B16 melanoma; CM: conditioned media; ELISA: enzyme-linked immunosorbent assay; HSE: hepatic sinusoidal endothelium; VEGF: vascular endothelial growth factor; IL-18: interleukin-18; RVL: resveratrol; VCAM-1: vascular cell adhesion molecule-1}

\section{Acknowledgements}

This work was supported in part by grants from the Spanish Ministry of Science and Innovation (SAF2006-09341), Basque Government Department of Education (IT-487-07) and ISCIII (ADE09/90041) to F. Vidal-Vanaclocha.

\section{Author details}

${ }^{1}$ Innoprot SL, Bizkaia Technology Park, Derio, Bizkaia, Spain. ${ }^{2}$ University of the Basque Country, School of Medicine and Dentistry, Bizkaia, Spain.

${ }^{3}$ Pharmakine Ltd, Bizkaia Technology Park, Bizkaia, Spain. ${ }^{4}$ CEU-San Pablo 


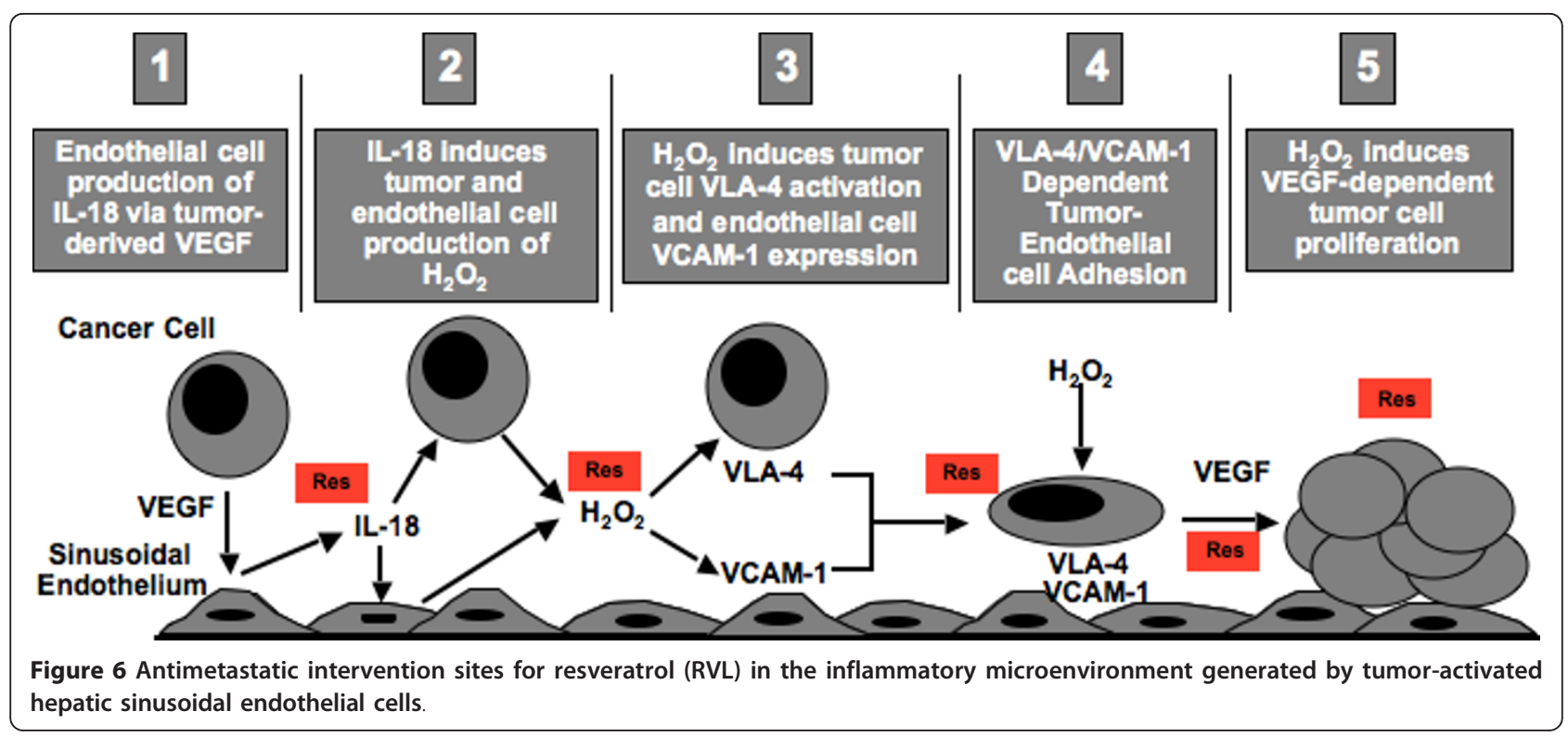

University School of Medicine, Institute of Applied Molecular Medicine (IMMA), Boadilla del Monte, Madrid, Spain.

\section{Authors' contributions}

CS performed most of in vitro and in vivo studies and contributed to manuscript preparation; EO contributed to in vivo studies and to manuscript preparation; EE, NG, MV and LM contributed to in vitro studies; FW conceived of the study, participated in its design and coordination, and wrote this manuscript. All authors have read and approved the final manuscript.

\section{Competing interests}

The authors declare that they have no competing interests.

Received: 14 October 2010 Accepted: 12 May 2011

Published: 12 May 2011

\section{References}

1. Balkwill F, Mantovani A: Inflammation and cancer: back to Virchow? Lancet 2001, 357:539-45.

2. Vidal-Vanaclocha F: The prometastatic microenvironment of the liver. Cancer Microenvironment 2008, 1:113-29.

3. Burns J, Yokota T, Ashihara H, Lean ME, Crozier A: Plant foods and herbal sources of resveratrol. J Agric Food Chem 2002, 50:3337-40.

4. Jang M, Cai L, Udeani GO, Slowing KV, Thomas CF, Beecher CW, Fong HH, Farnsworth NR, Kinghorn AD, Mehta RG, Moon RC, Pezzuto JM: Cancer chemopreventive activity of resveratrol, a natural product derived from grapes. Science 1997, 275:218-20.

5. Bishayee A, Barnes KF, Bhatia D, Darvesh AS, Carroll RT: Resveratrol suppresses oxidative stress and inflammatory response in diethylnitrosamine-initiated rat hepatocarcinogenesis. Cancer Prev Res 2010, 3:753-763.

6. Bishayee A: Cancer Prevention and treatment with resveratrol: from rodent studies to clinical trials. Cancer Prev Res 2009, 2:409-418.

7. Johnson GE, Ivanov VN, Hei TK: Radiosensitization of melanoma cells through combined inhibition of protein regulators of cell survival. Apoptosis 2008, 13:790-802

8. Bishayee A, Waghray A, Barnes KF, Mbimba T, Bhatia D, Chatterjee M, Darvesh AS: Suppression of the inflammatory cascade is implicated in resveratrol chemoprevention of experimental hepatocarcinogenesis. Pharmaceutical Research 2010, 27:1080-1091.

9. Ivanov VN, Partridge MA, Johnson GE, Huang SX, Zhou H, Hei TK. Resveratrol sensitizes melanomas to TRAIL through modulation of antiapoptotic gene expression. Exp Cell Res 2008, 314:1163-76.
10. Zhang Q, Tang X, Lu OY, Zhang ZF, Brown J, Le AD: Resveratrol inhibits hypoxia-induced accumulation of hypoxia-inducible factor-1alpha and VEGF expression in human tongue squamous cell carcinoma and hepatoma cells. Mol Cancer Ther 2005, 4:1465-74.

11. Huang C, Ma W, Goranson A, Dong Z: Resveratrol suppresses cell transformation and induces apoptosis through a p53-dependent pathway. Carcinogenesis 1999, 20:237-42.

12. Yang Z, Yang S, Misner BJ, Chiu R, Liu F, Meyskens FL Jr: Nitric oxide initiates progression of human melanoma via a feedback loop mediated by apurinic/apyrimidinic endonuclease- $1 /$ redox factor- 1 , which is inhibited by resveratrol. Mol Cancer Ther 2008, 7:3751-60.

13. Vidal-Vanaclocha F, Fantuzzi G, Mendoza L, Fuentes AM, Anasagasti MJ, Martín JJ, Carrascal T, Walsh P, Reznikov LL, Kim S-H, Novick D, Rubinstein M, Dinarello CA: IL-18 regulates IL-1 beta-dependent hepatic melanoma metastasis via vascular cell adhesion molecule-1. Proc Nat Acad Sci USA 2000, 97:734-39.

14. Vidal-Vanaclocha F, Amezaga C, Asumendi A, Kaplanski G, Dinarello CA: Interleukin-1 Receptor Blockade Reduces the Number and Size of Murine B16 Melanoma Hepatic Metastases. Cancer Res 1994, 54:2667-72.

15. Carrascal TL, Mendoza M, Vacarcel C, Salado E, Egilegor N, Telleria F, VidalVanaclocha, Dinarello Charles: Interleukin-18 binding protein reduces B16 Melanoma Hepatic Metastasis by neutralizing the adhesiveness and growth factors of sinusoidal endothelial cell. Cancer Res 2003, 63:491-7.

16. Mendoza L, Carrascal T, De Luca M, Fuentes AM, Salado C, Blanco J, VidalVanaclocha F: Hydrogen peroxide mediates vascular cell adhesion molecule-1 expression from interleukin-18-activated hepatic sinusoidal endothelium: implications for circulating cancer cell arrest in the murine liver. Hepatology 2001, 34:298-310.

17. Vidal-Vanaclocha F, Mendoza L, Telleria N, Salado C, Valcarcel M, Gallot N, Carrascal T, Egilegor E, Beaskoetxea J, Dinarello : Clinical and experimental approaches to the pathophysiology of interleukin-18 in cancer progression. Cancer Metastasis Rev 2006, 25:417-34.

18. Olaso E, Salado C, Egilegor E, Gutierrez V, Santisteban A, Sancho-Bru P, Friedman SL, Vidal-Vanaclocha F: Proangiogenic role of tumor-activated hepatic stellate cells in experimental melanoma metastasis. Hepatology 2003, 37:674-85

19. Shibata M, Hirota M, Nozawa F, Okabe A, Kurimoto M, Ogawa M: Increased concentrations of plasma IL-18 in patients with hepatic dysfunction after hepatectomy. Cytokine 2000, 12:1526-30.

20. Mendoza L, Valcarcel M, Carrascal T, Egilegor E, Salado C, Sim BK, VidalVanaclocha F: Inhibition of cytokine-induced microvascular arrest of tumor cells by recombinant endostatin prevents experimental hepatic melanoma metastasis. Cancer Res 2004, 64:304-10.

21. Kimura $Y$, Okuda $H$ : Resveratrol isolated from Polygonum cuspidatum root prevents tumor growth and metastasis to lung and tumor-induced 
neovascularization in Lewis lung carcinoma-bearing mice. J Nutr 2001, 131:1844-9.

22. Busquets S, Ametller E, Fuster G, Olivan M, Raab V, Argilés JM, LópezSoriano FJ: Resveratrol, a natural diphenol, reduces metastatic growth in an experimental cancer model. Cancer Lett 2007, 245:144-8.

23. Castillo-Pichardo L, Martínez-Montemayor MM, Martínez JE, Wall KM, Cubano LA, Dharmawardhane S: Inhibition of mammary tumor growth and metastases to bone and liver by dietary grape polyphenols. Clin Exp Metastasis 2009, 26:505-16.

24. Ara C, Kirimlioglu H, Karabulut AB, Coban S, Ay S, Harputluoglu M, Kirimlioglu V, Yilmaz S: Protective effect of resveratrol against oxidative stress in cholestasis. J Surg Res 2005, 12:112-7.

25. Kasdallah-Grissa A, Mornagui B, Aouani E, Hammami M, Gharbi N, Kamoun A, El-Fazaa S: Protective effect of resveratrol on ethanol-induced lipid peroxidation in rats. Alcohol and Alcoholism 2006, 41:236-9.

26. Kawada N, Seki S, Inoue M, Kuroki T: Effect of antioxidants, resveratrol, quercetin, and $\mathrm{N}$-acetylcysteine, on the functions of cultured rat hepatic stellate cells and Kupffer cells. Hepatology 1998, 27:1265-74.

27. Tarhini AA, Millward M, Mainwaring P, Kefford R, Logan T, Pavlick A, Kathman SJ, Laubscher KH, Dar MM, Kirkwood JM: A phase 2, randomized study of SB-485232, rhIL-18, in patients with previously untreated metastatic melanoma. Cancer 2009, 115:859-68.

28. Cao Q, Cai W, Niu G, He L, Chen X: Multimodality imaging of IL-18binding protein-Fc therapy of experimental lung metastasis. Clin Cancer Res 2008, 14:6137-45.

29. Cho D, Song H, Kim YM, Houh D, Hur DY, Park H, Yoon D, Pyun KH, Lee WJ, Kurimoto M, Kim YB, Kim YS, Choi I: Endogenous interleukin-18 modulates immune escape of murine melanoma cells by regulating the expression of Fas ligand and reactive oxygen intermediates. Cancer Res 2000, 60:2703-9.

30. Schwarz A, Maeda A, Ständer S, van Steeg H, Schwarz T: IL-18 reduces ultraviolet radiation-induced DNA damage and thereby affects photoimmunosuppression. J Immunol 2006, 176:2896-901.

31. Amin MA, Mansfield PJ, Pakozdi A, Campbell PL, Ahmed S, Martinez RJ, Koch AE: Interleukin-18 induces angiogenic factors in rheumatoid arthritis synovial tissue fibroblasts via distinct signaling pathways. Arthritis Rheum 2007, 56:1787-97.

32. Yumoto E, Higashi T, Nouso K, Nakatsukasa H, Fujiwara K, Hanafusa T, Yumoto Y, Tanimoto T, Kurimoto M, Tanaka N, Tsuji T: Serum gammainterferon-inducing factor (IL-18) and IL-10 levels in patients with acute hepatitis and fulminant hepatic failure. J Gastroenterol Hepatol 2002, 17:285-94.

doi:10.1186/1479-5876-9-59

Cite this article as: Salado et al: Resveratrol prevents inflammationdependent hepatic melanoma metastasis by inhibiting the secretion and effects of interleukin-18. Journal of Translational Medicine 2011 9:59.

\section{Submit your next manuscript to BioMed Central and take full advantage of:}

- Convenient online submission

- Thorough peer review

- No space constraints or color figure charges

- Immediate publication on acceptance

- Inclusion in PubMed, CAS, Scopus and Google Scholar

- Research which is freely available for redistribution 